\title{
O pião e o ponto final
}

VER NAVIOS. SÃO PAULO: NANKIN, 2007

de Airton Paschoa

PRISCILA FIGUEIREDO

"Pião" e "Ponto final", este praticamente subseqüente ao primeiro texto, são como a portada de Ver navios, sobre a qual formam uma alegoria dupla: vivacidade e parada, tendência centrífuga e convergência ensimesmada. Feitas da mesma matéria e designativas de estados que se alternam, essas alegorias se entrelaçam como peças de uma charneira. O pião é o ponto final que saiu de seu retraimento redondinho e pesado, ainda que seja para girar em torno de si, como se o reanimassem novas expectativas narcísicas. O ponto final é o ponto de apatia, decerto o estado posterior àquele, o resultado fisionômico de um trabalhoso recolhimento de energia outrora dispersa para outros lugares, como um pião que, em suas revoluções, olhasse para todos os lados: "Era uma vez um tipinho que se concentrou tanto, mas tanto, que terminou num ponto. E tão pesado, mas tão pesado ficou que nada, ninguém o removia".

Segundo penso, a expressão é tanto mais bem-sucedida no livro quanto mais tende ao ataráxico ponto final. A representação do interesse acordado por outros objetos, ainda que entre eles esteja o próprio eu, agora mais depressivamente ansioso que depressivamente melancólico, nem sempre tem a mesma qualidade da que vemos no primeiro caso. Mas mesmo isso não deixa de merecer nosso cuidado e, na verdade, parece misteriosamente se articular com a parte de êxito no livro - parte que vale por muitos livros.

A série dedicada ao irmão poderia ser filiada à zona da obra em que decide o caráter ou caractere de ponto, que imprime à prosa o seu modo e ritmo. Mas o irmão e o narrador são também como duas alegorias complementares: um, volátil, se suspende no ar; outro, grave, pesado, rasteja. O belíssimo "Golpe de ar" é de uma leveza triste, pois o irmão, que em outros momentos uiva, sonha, quer ser artista, que enfim não tem os pés no chão e não resiste ao que lhe dá na veneta, agora “deu de 
levitar", para a perplexidade do encaramujado narrador, que aguarda instruções: aí, nesse outro meio onde você está, aí no ar, não haverá também necessidade? Você não precisa de uma blusa? O medo também não existe aí? Parece que lá é como aqui; o irmão pede o cachecol, com a fisionomia indefinível dos mortos que nos aparecem em sonho e desmancham, e com eles o aprazível lugar em que estão, tão logo lhe perguntemos se é bom ali. $O$ irmão que sonha acordado levita; 0 irmão "incapaz de resistir [...] a uma boa cama" ("Ecce momo") se arrasta como um molusco (v. "Caracol" " "O balde"). Não deixam de, cada qual, realizar sua essência. No caso do eu quietista, processa-se o endurecimento do corpo, a formação de cal cificações. Ou de placentas. A reduzida movimentação pode ser de velho como de bebê.

Há dias que acordamos até o pescoço sonhosos. Uma pessoa desconhecida, uma história mal contada, uma vida entrevista... Mal nos mexemos, o corpo enterrado nas cobertas, mas é tarde. O sol vem nascendo e secando os restos de placenta. Afundamos no dia esuas covardias. Em pouco estarátudo esquecido. ("Carpe noctem")

A cama dá à luz a alguém disposto a recomeçar, a uma promessa gestada na calada da noite; na cama se enterra, se embotam os sonhos. O "afundamos no dia" pode ser "afundamos na cama", conforme um movimento comum até mesmo a um verme ("De vez em quando aponta um verme e logo se recolhe desapontado", de "Parada"); pode ser que se afunde no dia mesmo, mas um dia em que o tempo não vale muita coisa.

A insistência com que acorrem tais imagens, não propriamente novas em si mesmas, e a constelação lingüística que as produz lhes dão frescor, frescor que é um corredor de mão dupla, pois ele assimila e despede a ordem do dia. Em autores fundamentais da literatura do século XX, como Thomas Mann e Kafka, para não falar de Proust, a vida horizontal (muito simplesmente, a vida na cama) aparece com freqüência. Ela pode indicar que as energias civilizatórias estão em recesso. A suma felicidade que Hans Castorp, de $A$ montanha mágica, sente com uma espreguiçadeira perfeitamente anatômica não é muito diferente da satisfação que, em Vernavios, pode-se ter com a restauração de uma poltrona. É o caso de "Reforma gregária" (forma substitutiva muito decaída, compensaçãozinha paronomástica e imaginária do desejo de que o entusiasmo fosse produzido antes pelareforma agrária). Em ambos os casos a acomodação à doença e à vida fisiológica, que se resume a comer e dormir (como em "Ecce momo"), é mais fácil do queo decoro gostaria de admitir. Mas no autor alemão a prosa, o narrador e certos personagens não deixam de mostrar e às vezes de francamente combater o que se afigura como tendências anti-sociais, mórbidas, a 
[1] Do que dá parte, por exemplo, Lavoura arcaica, de Raduan Nassar. O severo regime do pai e sua domesticação do tempo se liga a um contexto específico, endogâmico, rural, de imigrantes libaneses. esse relevo do corpo e suas funções. Ainda que a Razão possa aparecer como uma figura também corroída e caricata, como Settembrini, ela contribui para soerguer, e muito, o foco narrativo, ponto culminante do humanismo burguês, embora em crise.

Por outro lado, nos textos de Airton a transgressão efetuada já não é, nessa altura da história, tão forte a ponto de o transformar literalmente (picturalmente) em inseto. Em $O$ processo, $O$ castelo, $A$ metamorfose, de Kafka, vemos ora chegar à cama a notícia mais importante, um veredito; ora pessoas sem nenhuma intimidade entre si fazerem contratos de trabalho ou revelações excepcionais estando sentadas na cama. Um leito pode ser compartilhado por hóspedes que não se conhecem. Por fim, pode-se não sair mais dele, e a hora perigosa para isso é precisamente a hora em que toca o despertador. Tão perigosa como aquela do conto de fada em que se vira abóbora. Gregor Samsa talvez tenha resolvido não cumprir o mandamento e pagar para ver, isto é, não se levantar cedo. Ignorar o interdito equivaleria a realizar o conteúdo de uma possível fórmula disciplinadora, ouvida desde a infância. Imaginemos uma: se não sair da cama agora, vai virar um bicho nojento. No livro de Airton, não se chega a produzir uma imagem que incorpore tal grau de repugnância - talvez porque a formação do caráter aqui não tenha estado tanto sob o encanto de tais sentenças ameaçadoras, talvez porque no Brasil não tenha havido de modo geral uma ética do trabalho generalizada, que se prevalecesse, para a garantia de sua perpetuação, de coerções dessa ordem; talvez porque muitos trabalhadores do capitalismo globalizado e sobretudo do chamado setor de serviços, que inclui os de natureza intelectual, normalmente fazem o seu horário, passível de ser cumprido nos limites do próprio espaço doméstico. Podem não precisar até mesmo sair da cama, com um laptop sobre as cobertas. E, se saírem da cama tarde, poderão compensar isso de alguma forma, pois a flexibilização de sua rotina é queé a regra, e espera-se que o senso de dever esteja muito internalizado.

O fatoéqueo poder de sugestão da sentença ameaçadora nãoé mais tão grande. E, como dissemos, talvez nunca tenha sido no Brasil, a não ser em contextos muito específicos ${ }^{1}$. No divertido samba "Cocoricó", cantado por Clementina de Jesus, trava-seo seguinte diálogo: "Levanta nego, que só faltam dez pras seis/[...] ô nega, me deixa dormir, eu hoje me sinto cansado/ o relógio da parede talvez esteja enganado [...]". Põe-se em questão a forma universalmente pactuada de medida do tempo - que é por certo uma convenção, mas é como se nem sempre a tivéssemos levado muito a sério. Essa ilusão, de caráter civilizatório, não colou perfeitamente. Vira e mexe se desacredita um pouco das estratégias que buscam dar feição ao tempo, deixá-lo visível. Mas, de resto, não é o que fazem hoje os ideólogos da flexibilização dos turnos de trabalho, os filósofos de RH, para quem o sentimento de duração 
é também uma distensão do espírito? Como o nego interpelado por Clementina, argumentam: o relógio pode se enganar, o importanteéo que eu sinto lá no íntimo. O importante é o que você sente que trabalhou. E pode ir pra cama quando quiser. O nosso malandro metafísico já sabia disso, já perfurava a casca do relógio - o que não quer dizer que ele não dava duro. Mas o fazia como certos operários de hoje. Estes, indiferentes ao relógio, flexibilizados, não vêem o tempo, não vêem o quanto exatamente labutam. Sua rotina é turva, sem marcos que a clarifiquem; os cobertores da cama podem se misturar com apetrechos de escritório. Ou no escritório pode haver um colchãozinho para se trabalhar virando a noite.

Na longa série de Ver navios em que a pessoa está derreada, com a postura um tanto frouxa, não sabemos precisar se se trata de um aposentado (por tempo ou invalidez), de um desempregado, de um terceirizado. Pode por vezes ganhar mais contorno a figura de um escritor improdutivo, doente (porque parou de fazer as coisas, ou parou porque ficou doente), como em "Auto-ajuda". De toda maneira, se há algo que porvezes irmana no mundo real todas as categorias mencionadas (desocupado, flexibilizado, pensionário), é uma espécie de depressão psíquica, em razão talvez da fragmentação social, da falta de espaços concretos para a prática de relações intersubjetivas, da perda de seguridade (na proporção brasileira que seja, como aparece em "Elegia") $-e$, muito provavelmente também, em razão do marasmo político nas democracias atuais, especificamente do marasmo brasileiro, a que Airton parece se dirigir umas tantas vezes, de modo alusivo. A vida no livro que de fato se configura é muito mais a vida privada, e então é natural que sobrevenham imagens de morte para lidar com uma experiência de não-aparecimento².

Essa depressão é um estado interno do livro e está indiciada, chamando a atenção para si, por meio de vários títulos, que são como diferentes aspectos dela: dependência, ambulância, auto-ajuda, persiana, aleijadinho, carpe noctem, casco, caracol, gás encanado, momo, divã ocidental, parada (ilha também, de algum modo). Em todos a pessoa está mais ou menos estirada ou acantonada, dificilmente ereta, dificilmente em movimento. Está-se apavorado com as sirenes da cidade (São Paulo, decerto), entrevista pela fresta da janela, è̀s vezes incomodado com um estranho ruído endógeno: é a labirintite. Esta adquire, no contexto presente, algo de mau presságio;é com alguma naúsea que o narrador nos informa dela ("Ambulância"). O mau traquejo com o mundo lá fora se transformou em patologia, dificuldade mórbida de se localizar no espaço, mesmo o mais protegido. As sirenes brotam do próprio ouvido. Se não éa labirintite,é outro mal-estar, apenas na aparência endógeno: "Não estou preso, mas o peso na cabeça torna a cela intransitável" ("O caracol"). Se preso não significa aqui "acorrentado",
[2] Na formulação de Hannah Aren$\mathrm{dt}$ : "Uma vez que a nossa percepção da realidade depende totalmente da aparência e portanto da existência de uma esfera pública na qual as coisas possam emergir da treva da existência resguardada, até mesmo a meia-luz que ilumina a nossa vida privada e íntima deriva, em última análise, da luz muito mais intensa da esfera pública" (A condição humana.Trad. Roberto Raposo. Rio de Janeiro: Forense Universitária, 1997, p. 61). 
[3] Essa dialética do expressionismo está exposta por Peter Szondi na Teoria do drama moderno. "aguilhoado", então o caso é de contradição lógica ou de esquizofrenia: não estou preso, mas a cela. Esta são favas contadas - preso ou não, estáse sempre numa cela? O que dá a qualidade de preso é a intransitabilidade do cômodo, que é cela, ou célula, na qual se está encerrado por vontade própria e que talvez seja extensão da pessoa. Não deliberado é a impossibilidade de andar nela. Mas na verdade o hábito anti-social produziu a afecção, como no caso da labirintite: o abrigar-se constante do mundo se tornou dificuldade de estar até com o corpo, sobre o qual a cabeça tomou o peso de uma casa, a que ele está atado até o fim de seus dias, como se diz que o caracol é sua própria casa.

Essas operações poderiam nos levar a pensar numa configuração expressionista: o eu que se destacou do mundo e que pretendia alcançar a sua pura humanidade, sem data e nome (para fora do individualismo), se torna acanhado em razão da mesma separação. A abstração lhe tira profundidade; e o mundo também aparece mais ralo, como numa poça d'água, enfraquecido de determinações 3 . No entanto, por mais que o resultado de tal abstração seja a perda de humanidade do homem (ou talvez em razão de isso ocorrer), certo tremor metafísico repassa o expressionismo de uma maneira geral. Esse páthos não tem lugar na auto-ironia ora pachorrenta, ora mais vivaz, do narrador de Ver navios - que, no entanto, não deixa de constatar que a realidade, e a realidade de uma cidade como São Paulo, pode deformar os seres humanos com muita desenvoltura e os transformar também, como o expressionismo, em metonímias, ou, mais do que isso, em sinédoques: em estranhas partes que vibram e gritam, e lembram mal o humano (como a mulher de "O grito"). Mas quem é pego por essa estridência também está descompensado, e isso é que o faz correr para seu abrigo nuclear.

O sujeito aqui não tem uma estatura realmente adulta: ou está em desaparecimento precoce ou tem uma frágil aparição no mundo, ao modo de um bebê, a quem os lençóis envolvem como uma placenta suja. A auto-imagem do narrador como sendo a de uma espécie de mendigo também não é inusual, como no excelente trecho:

[...] Difícil pra eles, que me espiam com dó de dar pena. Epra mim também, um pouco. Não pelo olhar de ódio que me atropela de repente do sofá. Pulo, como que chutado por uma idéia, e caio fora. Fico no banco, adormentando no solzinho, e me esqueço contando formiga. Uma atrás da outra, engraçado, não seipor quê, choro, ou durmo, não lembro. Sóvolto quando ofrio ou a fome me expulsam de novo pra dentro ("Auto-ajuda").

Mendigo de casa, alguma coisa o faz se sentir, como lemos no título de outra peça do livro, um tanto aleijadinho, ou um tanto emporcalhado, ou até meio morto. Apenas espera que a pá de cal lhe dê um arremate: 
Nunca lembro como adormeci, se de costas ou de bruços, se caí em mim no chão ou no teto, os braços cruzados ou abertos. O olho arde sempre, lembro, assim ou assado. Por isso aprendi a abri-lo e fechá-lo por dentro. O olho de peixe morto permite vigiar o desterro das unhas, dos cabelos, da barba, a vibração dos órgãos, surda, dos mais mudos aos mais sujos [...]. Pode porém subir e descer sem paz a pá de cal que ninguém liga, só sabem deslizar laje adentro... ("Aleijadinho").

Com a percepção de um mutilado, ou de um deprimido, ou de um bebezinho, ou de alguém que está mais pra lá do que pra cá, de fato não se produz a imagem mais clara deste mundo, como já apontava Rodrigo Naves na orelha do livro, lembrando, porém, que esse mundo anda bem difícil de representar, independentemente da ataraxia do narrador. Quanto aos outros, que não esse eu que nos avisa potentemente de sua imobilização progressiva, não diferem muito (como em "Auto-ajuda") dos humanos de que só vemos a perna nos desenhos de Tome Jerry. E o espaço público, por sua vez, éalgo contra o que se busca proteção: "Enjoa o mar de prédios, de carros, de caras. [...] Em algum lugar se mata, se morre, se tenta viver. Em algum lugar pega fogo. Mas não é aqui, descansemos ('Persiana')".

Essa retração em relação ao mundo, favorecida por um tempo "flexibilizado", seliga à tendência lírica aqui.E, naverdade, quanto maior a concentraçãoem si mesmo, quanto mais a pessoa desinvesteos objetos exteriores de seu interesse, mais a linguagem se desbasta da retórica da qual ela se torna presa em muitos momentos. $\mathrm{O}$ impulso para fora do auto-encasulamento ("vida é movimento", diz-se em "Auto-ajuda"), ou o impulso para algum movimento em geral, mesmo que seja para o protesto, a crítica, a manifestação de ódio, algumas vezes não tem êxito igual. Nesse caso, domina a fúria de trocadilhos, rimas, metáforas encadeadas, paronomásias, aliterações, engenhosidade acompanhada de uma curiosa aceleração no ritmo da prosa, como se esta se sentisse incentivada, encantada com as possibilidades de que se tornou autoconsciente. Tenho a impressão de que, em tal contexto, o molto vivace do andamento, que não deixa de manifestar um impulso para a vida, bem estilizado em "Poema do caso perdido" (o amor erótico aparece como uma das poucas perspectivas de humanização4), indica por vezes que o significante lingüístico tomou o carro na frente dos bois e fica meio esbaforido. Em "Algodão doce", "Aniversário", "Eldorado", "Campanha do agasalho", "Triste Venise”, "Credibilidade”, "Elegia burguesa", "Odisséia”, a frase saltita alegremente sobre os escombros do enunciado. O problema não está no contraste em si (em arte o problema não éo meio em si), mas no fato de esse contraste não colaborar aqui para dar expressão ao sentimento que se tem das coisas. Mesmo textos mais homogeneamente bons, como "Metereologia" (a grafia
[4] Toma-se por vezes emprestada, para dar forma no entanto a uma impressão muito contemporânea, a estilização da vontade de ritmo dissoluto, mais presente de fato na poesia modernista brasileira dos anos 1930 que dos anos 1920, por mais que esta alardeasse imagens carnavalescas. Essa vontade podia ser a de picar a mula, ir para Pasárgada, entregar-se ao amor louco etc. Com essa observação, em parte tenho em vista o ensaio de Mário de Andrade, em Aspectos da literatura brasileira, sobre a poesia de 1930. 
é essa mesma), podem às vezes se prejudicar por um trocadilho (no caso, expio/espio, que depende mais do olhar que dos ouvidos), a quem é dada a tarefa, desnecessária na verdade, de um remate anticlimático, no interior do qual se topa, não obstante, com uma discreta, mas nem por isso imperceptível, chave de ouro. A astúcia trocadilhista vem desmanchar a circunspecção lírica, e não é a troco de algo mais. Processo de certo modo inverso ocorre em "Ecce momo", que é todo organizado por metáforas encadeadas: na confissão dirigida a Deus, o que já puxa para cima o estilo (e o título, que é meio latim e um chiste por si mesmo), diz que suas promessas foram para o ralo, mas ele mesmo não, porque foi ficando branco e desazimado (ou desanimado) como hóstia balofa (fermentada, já que não é ázima) e esta não passa pelo ralo; o sangue dessa hóstia, que não é bem o corpo de Cristo, foi tomado de diabetes. Não tendo sangue nenhum que umedeça essa carne, ele agora esfarinha, ressecado. Mas a última frase, ao gosto da poesia marginal ou da literatura beat, surpreendentemente rebaixada quanto à elocução anterior, de que já não estava ausente entretanto uma autoironia gozada, embora não destruidora da solenidade, dá um banho de água fria na sutileza e arte de engenho com que o narrador vinha se retratando: "e não sei se vai dar pra encarar outra paixão". A ruptura de estilo é espantosa, as metáforas cessam, mas o efeito é no fim das contas bom. Faz tudo parecer a fala versátil de um bêbado num boteco, hábil em passar por várias maneiras e registros lingüísticos, habilidade que recebe uma lambada final de saideira.

Também há os casos em que se tira partido da literalidade de uma expressão idiomática, ou de um modismo corrente no jargão da política ou das ONGs, como "Inclusão digital", que se revela um exame de próstata. Numa situação social, seria engraçado, pois ressalta a tolice dessas fantasias gramaticais - o que se pretende como inclusão digital não é inclusão de dedo ou inclusão a ser feita digitalmente, mas a democratização do acesso à tecnologia digital. No entanto uma construção assim seria de fato um pouco grande, e certo abreviamento das mediações, como a metonímia,é justificado, agiliza a comunicação. $\mathrm{O}$ problema é que a construção muito sintética parece compactuar com o fato de a ação designada pretender se afirmar como panacéia e sair do seu modesto, embora justo, raio de ação.A expressão tem de sustentar um enunciado complexo demais, que requereria mais preposições e substantivos do que tem à disposição. O que se convencionou chamar de política de inclusão digital se alça então a sucedâneo da inclusão social, não obstante o fato de que inicialmente se propunha a cuidar de algo muito preciso.

Por mais que indique tudo isso,esse chiste de Airton mostra como a fixação escritaé impiedosa, pois nos dá os mecanismos de voltar, repetir, pausar. Mesmo na vida social não é comum fazer um dito engenho- 
so ser precedido pela expressão com o perdão pelo trocadilho. É porque, conquanto possa estar longe da formalidade maior do texto escrito, o trocadilho tem efeito facilitadore, às vezes, pouco objetivante. Trata-se de um recurso com o qual se pode saltar no tempo e no espaço e desconsiderar relações, aproximando coisas afastadas, inclusive quanto à categoria. Pôr em presença palavras foneticamente similares com o fim de desvendar o segredo do que uma delas indica em certo momento requer presença de espírito e o domínio de um amplo léxico. Há algo de gênio nessa operação, mas, como o perigo que ronda as percepções muito rápidas, pode-se cair no conformismo. Conformismo formal inclusive: se o texto nasce e vive à custa de uma correspondência, pode morrer dela também, sem absorver outra seiva.

Há momentos em que a apropriação de um jargão para outros domínios da vida tem êxito, como em "Flexibilização". No caso, ela é das exigências de um sujeito de meia-idade ou mais em relação à moça de quem está à procura num anúncio. Mas trata-se também (e aqui está o humor) de flexibilização de virtudes mais tradicionalmente viris, como o cavalheirismo. Assim, ele não se importa, um tanto cinicamente e como Bentinho no penúltimo capítulo de Dom Casmurro, de a moça pegar ônibus, ser calcante pede etc. Talvez o melhor resultado obtido nesse caso se deva à forma na qual o trocadilho caiu como luva, que é o anúncio. E, como este, os textos de Ver navios são de pequeno fôlego, diferentes, por exemplo, de Contostortos, primeiro livro do autor. A brevidade do espaço não é obstáculo para a consecução deste raciocínio de escambo, que na verdade só pede um pouco de calor humano e poesia: na era em que quase tudo seflexibiliza, inclusive a gramática, à qual também não é dado o luxo de processar o novo lentamente até poder nomeá-lo com expedientes mais vernáculos e menos bárbaros, contratos e relações que por certo tempo gozaram de solidez se tornam igualmente maleáveis.Assim também este anunciante: como ele aceita tudo (até tíquete-refeição e vale-transporte, poderíamos acrescentar), também é lícito que dele se aceite tudo: você, que me procurar, saiba que não necessariamente serei cavalheiro etc. Quero um pouco de aconchego, venha de onde vier, embora eu não vá fazer o meu amor ser precedido das formalidades depraxe, que não são mais praxe. Estou muito cansado (ouduro, ou avacalhado) para isso.

Se há uma elocução ansiosa para ir direto ao ponto, é a publicitária. Sua capacidade de síntese, em que a arte no século XX freqüentemente buscou se instruir para se despir de retórica, é destituição pura e simples de formalidade. Também a ironia de Airton vai aqui ao ponto e corrói muito mais do que parece à primeira vista.

Quando se trata de analisar as relações sociais na universidade, por exemplo, o caso volta a se complicar. A razão por que "Literatura e sociedade" (texto de certo modo também problemático) se sai melhor 
que "Butantã City" está provavelmente na tendência mais subjetivante, no fato de, afinal, o narrador não transpor o limiar entre ele e o grupo social que observa e se cerrar por fim a sua dificuldade de o fazer. Já no outro texto, busca-se mais objetividade - para descrever um processo, porém, mais difícil de se mostrar em sua totalidade num flash literário. Por certo a totalidade de um processo pode sobrevir, na vida cotidiana, em uma rápida visada, dependendo da imaginação, da memória e da cultura do observador. E nesse fenômeno residia, para Henry James, um argumento forte para opôr à necessidade da extensa pesquisa empírica que Zola via como indispensável ao artista para conhecer, e então formalizar, um certo objeto social com o qual estivesse pouco familiarizado. A problematicidade que observo aqui não é relativa à forma de percepção, fragmentária ou não, que deu gênese ao processo literário, mas ao modo de representação conforme o objeto. Não se trata de estética normativa - a questão é comparar o ímpeto de pesquisa do texto com o efetivo esclarecimento do leitor. E, no caso de "Butantã City", este é muito pequeno. A não ser que entre no jogo alusivo que o texto propõe. Essa é a única forma aqui de estabelecer conexões, de ver além das econômicas pinceladas. $O$ recurso à alusão como principal meio para capturar o todo de uma estrutura rende pouco nesse caso específico porque alcança o tema em vista como uma câmera que se detivesse menos no alvo e mais na pessoa que o acerta e sai correndo. É a pessoa correndo que vemos aqui,é o mesmo narrador que vinha nos ocupando, surpreendido, porém, no desejo de sair de cena e deixá-la com o mundo (um pequeno mundo que seja) que o aflige. Conquanto use o pretérito imperfeito e exiba um gesto objetivante, ele nos conta tão pouco desse mundo como alguém que queira revelar um mal que lhe fizeram, mas o faz genericamente, com abstrações - velhuscas, pois sua vibração imponente é uma energia que tende a acabar logo se não é armazenada em certas baterias - como vaidade, perfídia, inveja. No entanto, a dimensão de quanto o insuficientemente dito pede passagem e perturba a quem ia dar com a língua nos dentes é sugerida pelas pausas, um eventual ato falho, pela gesticulação excessiva, pelo riso nervoso etc. Seja como for, esse foi o tipo de metabolismo do que estava engasgado que o observador ou pessoalmente atingido julgou mais adequado, ou mais moral, realizar. Ficam uns resíduos aqui e acolá, a curiosidade do ouvinte se atiçou, mas talvez tenha sido melhor assim — interditar. Mas isso — na vida. Não obstante, há diferenças qualitativas entre cotidiano e arte, ou esta arte pelo menos.

De maneira análoga, são algo como aqueles traços sintomáticos que a alusão traz à tona no texto em questão, e não o segredo em si. O foco, a despeito do narrador, não está na universidade, mas nele. E isso é uma pena para nós agora porque já fora despertado o interesse 
para ela. Quando se fala em "fogueira de vaidades", sabemos mais ou menos de que se trata. Os de dentro da universidadee especificamente da USP, chamada pelo nome, acrescentam por sua conta mais concretude ao clichê; mas os de fora têm lá sua idéia também. O resultado é que se fica como já estava, e a expressão dá o tiro no próprio pé, posto sem querer em relevo. No fim, estamos em família — quem sabe precisar do que se está falando sabe um pouco mais, eé só. Mas a vida universitária, queé social também, merece ser literariamente pesquisada como qualquer outra. A consciência pública assim o deveria julgar. Como qualquer outra, essa vida pode fornecer leis gerais e nos instruir sobre nós, dentro ou fora da academia. Então perguntamos: 0 que se quer dizer exatamente comfogueira de vaidades, comferinas? Que fenômenos concretos fundamentais esse clichê acaba por dissolver? Porque ele os dissolve, mas vibra, um pouco demais para um clichê.É que um espírito novo o anima, sem achar expressão.

PRISCILA FIgUeIREDO é autora de Em busca do inespecifico (Nankin, 2001). 